usual absence of œdema. If œdema does supervene in these cases, it is usually cardiac, not renal, due to heart failure, secondary to the rise of blood-pressure.

Now what pathological processes will give rise to this condition of renal failure ? The answer is almost any pathological process which may affect both kidneys. Thus occasionally it may be produced by bilateral renal calculi or bilateral renal tuberculosis. Congenital cystic disease of the kidneys is a not uncommon cause. Chronic prostatic obstruction with bilateral hydronephrosis will produce it, as also will neurological conditions associated with chronic retention of urine-I saw a case in a man with tabes only the other day. A few cases have been described lately in which great hypertrophy of the bladder has been found with bilateral hydronephrosis, but no organic obstruction of the urethra has been present. Such cases have been attributed to an achalasia or a failure of the bladder sphincter to relax-I saw a case of this kind which was admitted to hospital with uræmia not so very long ago. Then again, the changes which take place in the arteries of the kidney as the result of primary high blood-pressure starve the kidney of blood and leads to the so-called secondary ischæmic nephritis-this presents the same clinical picture. Then you have cases of this kind which may follow a true infective or toxic nephritis.

There are, however, some cases which present this clinical picture and in which no surgical cause can be found, in which primary hyperpiesis seems improbable, and in which there is no history of previous renal disease. Such cases, and this is an example, appear to be a primary fibrosis of the kidney, and have been described by Volhard and Fahr as malignant sclerosis. Lead sometimes appears to play a part in the æetiology of this condition, and if you ask the patient he will tell you that he worked in lead works for many years until he was advised to give it up on account of recurrent attacks of lead colic.

\title{
A CASE FOR DIAGNOSIS.
}

BY DR. W. BURTON-WOOD, M.D., M.R.C.P., Physician to Out-Patients, City of London Hospital, Diseases of Heart and Lungs.

FRED E., aged I5, waterworks assistant, enjoys good health, but has been kept under medical observation for two years on account of a pulmonary abnormality.

Previous

History.

At the age of 5 , when his mother was attending with the patient at right lung." a school inspection, she was told that he had "a black patch on the

At the age of 13 , when again undergoing medical inspection at school, the doctor detected an abnormal condition of the right lung and referred the case to hospital. There is no history of bronchial catarrh or pneumonia.

\section{Family History. Nil ad rem.}

At the age of 13 he attended the Victoria Park Chest Hospital. At

History of

Present

Condition. this time he looked well, but complained that at times he suffered from pain in the right side of the chest. This was never severe and did not interfere with school or play. Since this time he has enjoyed good health, but has been kept under observation. He was admitted to hospital about June, I930, for a short period for purposes of special investigation.

Present Condition.

The patient is a healthy looking lad and well nourished. The chest is well formed and symmetrical. There is a slight diminution of expansion 
at the right base. Vocal fremitus is absent posteriorly below the angle of the scapula. On percussion there is absolute dullness below the angle of the scapula on the right side and over the lower half of the right axilla. Breath sounds and vocal resonance are absent over the same area. There is no cardiac displacement.

The physical signs suggest the possibility of $(a)$ a pleural effusion,

Diagnosis.

(b) thickened pleura resulting from a previous pleurisy, $(c)$ a massive fibrosis of the right lower lobe, or $(d)$ neoplasm. The first three conditions are not uncommon in childhood, the fourth is extremely rare.

(a) Pleural effusion is unlikely because of the history of the case (the condition has persisted during ten years) and because there is no cardiac displacement towards the opposite side of the chest.

(b) Thickened pleura is unlikely because there is no history of acute pulmonary disease and there is no evidence of retraction of the chest or cardiac displacement towards the affected side. A thickening of the pleura sufficient to account for the physical signs would probably be accompanied by fibrosis and shrinking of the subjacent lung.

(c) The arguments just considered would also apply in the case of a fibroid lobe. In pulmonary fibrosis the breath sounds are usually weakened and not abolished. Crepitations of fibrotic type are usually heard, especially after coughing. The absence of a history of bronchopneumonia or attacks of pulmonary catarrh are also evidence against fibrosis.

(d) A pulmonary neoplasm would explain the physical signs and this explanation would obviate the difficulties just considered. It is necessary to obtain further evidence, however, before concluding that such a rare condition is the cause of the physical signs. The report of the hospital investigation was as follows :-

(i) X-ray Examination. - The skiagram showed a uniform opacity of the lower half of the right lung field. These appearances did not suggest either fluid or atelectasis, the upper margin of the opacity being convex.

(ii) X-ray examination after the induction of an artificial pneumothorax showed an oval opacity about the size of an ostrich's egg, with its long axis vertical. A lateral view showed that this occupied a posterinr position in the hemithorax. Its relationship to the lung, however, was not clearly defined.

(iii) On exploratory puncture the needle appeared to penetrate a solid tumour and no evidence of fluid was found.

(iv) Examination after lipiodol injection was not considered essential.

On the evidence, a diagnosis of an innocent solid thoracic tumour seems to be justified. Its situation and character indicate that it is probably a fibroma.

Treatment. As no medical treatment is possible, a decision must be made between leaving the tumour alone or attempting to remove it by operation.

(a) Non-interference. The patient has enjoyed good health during ten years; the tumour was of large size when the patient was first seen. It has not increased in size during the last two years. Operation risks are considerable and death might result from surgical interference.

(b) Improvements in surgical technique have lessened operative risks. Innocent thoracic tumours usually increase in size and ultimately prove fatal.

In the opinion of the demonstrator an expectant policy is indicated. 